\author{
Mikotaj Bartlomiejczyk \\ Przedsiębiorstwo Komunikacji Trolejbusowej \\ Sp. z o.o. w Gdyni \\ Politechnika Gdańska \\ Katedra Inżynierii Elektrycznej Transportu \\ Wydziat Elektrotechniki i Automatyki \\ Marcin Polom \\ Przedsiębiorstwo Komunikacji Trolejbusowej \\ Sp. z o.o. w Gdyni \\ Uniwersytet Gdański \\ Instytut Geografii \\ Wydziat Oceanografii i Geografii
}

\title{
Dwa lata eksploatacji trolejbusów $z$ bateryjnym źródłem zasilania w Gdyni
}

\section{Geneza pomysłu}

Przedsiębiorstwo Komunikacji Trolejbusowej w Gdyni od blisko piętnastu lat dokonuje sukcesywnej wymiany taboru, opartej o pojazdy niskopodłogowe. Pierwszy niskowejściowy trolejbus Jelcz M121MT został wprowadzony do eksploatacji w 1998 roku. W latach 2001 - 2002 zakupiono cztery całkowicie niskopodłogowe trolejbusy Solaris Trollino $12 \mathrm{~T}$ a od 2003 r. w parku taborowym zaczęły się pojawiać pojazdy wyposażone $\mathrm{w}$ napęd asynchroniczny, pierwszym z nich był Solaris Trollino 12AC wyposażony w układ napędowy czeskiej firmy Cegelec $[1,6]$. W 2008 roku rozpoczęto przygotowania do realizacji projektu „Rozwój proekologicznego transportu zbiorowego na obszarze metropolitarnym Trójmiasta". Jednym z elementów tego projektu był zakup 25 niskopodłogowych trolejbusów wyposażonych w autonomiczne źródło zasilania, co miało na celu zwiększenie niezawodności komunikacji trolejbusowej.

W trakcie prac studyjno-projektowych rozważano wyposażenie nowych trolejbusów w pomocniczy agregat spalinowy, baterie elektrochemiczne lub zasobnik superkondensatorowy. Zasadniczym argumentem decydującym o rezygnacji z zastosowania zasobnika superkondensatorowego była jego relatywnie niewielka pojemność, ograniczająca zasięg jazdy bezsieciowej do jednego kilometra [3, 5]. Czynnikiem przemawiającym na niekorzyść agregatu spalinowego były względy środowiskowe, czyli emisyjność oraz znaczny poziom hałasu generowany podczas pracy. Istotnym argumentem okazały się także aspekty eksploatacyjne - PKT Gdynia jest przedsiębiorstwem posiadającym w swoim parku taborowym wyłącznie trolejbusy, czyli pojazdy o napędzie elektrycznym. Skutkiem tego, zajezdnia trolejbusowa nie dysponuje kadrą ani zapleczem technicznym odpowiednim do eksploatacji pojazdów wyposażonych w silniki spalinowe. Należy także zwrócić uwagę na znaczny potencjał rozwojowy baterii elektrochemicznych, których cena jak i parametry techniczne ulegają ciagłej poprawie jako rezultat wzrostu popularności pojazdów elektrycznych.

Bazując na przedstawionych powyżej argumentach podjęto decyzję o zakupie trolejbusów wyposażonych w pomocniczy napęd akumulatorowy. $Z$ dostępnych na rynku technologii wybrano baterie niklowokadmowe. Podstawowym czynnikiem stojącym u podstaw tej decyzji była żywotność ogniw wykonanych w tej technologii potwierdzona doświadczeniami eksploatacyjnymi innych użytkowników. Zaletą baterii niklowo-kadmowych jest także ich duża przeciążalność prądowa, mająca kluczowe znaczenie w przypadku napędów trakcyjnych.

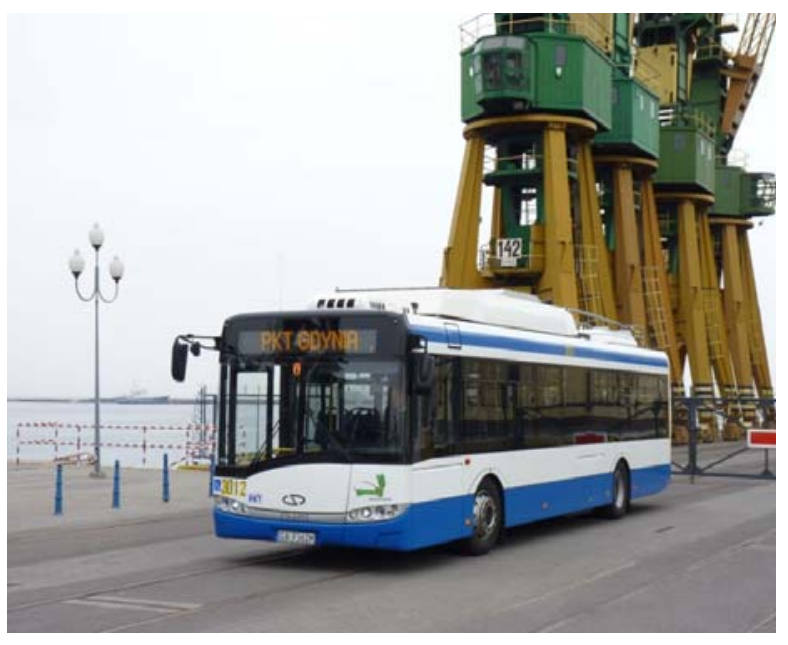

Fot. 1. Trolejbus Solaris Trollino 12 / Medcom wyposażony w baterie niklowo-kadmowe firmy SAFT.Autor: Marcin Połom 


\section{Realizacja projektu}

Pierwsze dwa prototypowe trolejbusy wyposażone w autonomiczny napęd bateryjny zostały zakupione przez PKT ze środków własnych, a dostarczone przez firmę Solaris w 2009 r. (fot. 1). W marcu 2010 roku rozstrzygnięto przetarg na dostawę kolejnych 25 sztuk pojazdów, także wyposażonych $\mathrm{w}$ pomocniczy napęd akumulatorowy, którego zwycięzcą okazała się ponownie firma Solaris [2].

W ramach obydwu zamówień dostarczone zostały trolejbusy Solaris Trollino 12 wyposażone w układ napędowy produkcji firmy Medcom. Dla celów zasilania awaryjnego znalazły zastosowanie baterie niklowo-kadmowe typu STH800 firmy SAFT. Baterie te są połączone $\mathrm{z}$ pozostałą instalację elektryczną $600 \mathrm{~V}$ za pomoca rezonansowego przekształtnika DC/DC, który w trakcie jazdy autonomicznej podwyższa napięcie baterii do napięcia znamionowego układu napędowego a w trakcie jazdy przy zasilaniu z sieci trakcyjnej pełni rolę ładowarki akumulatorów. Ponadto, przekształtnik ten zapewnia separację galwaniczną pomiędzy ogniwami a potencjałem sieci trakcyjnej. Baterie trakcyjne oraz przekształtnik sa umieszczone w tylnej części pojazdu (fot. 2). Trolejbus jest wyposażony $\mathrm{w}$ automatyczne odbieraki prądu umożliwiające przyłączanie i odłączanie się od sieci trakcyjnej bez konieczności ręcznego manipulowania przez kierowcę. Charakterystykę własności trakcyjnych przy jeździe autonomicznej przedstawiono $\mathrm{w}$ tab.1.

Tab. 1. Podstawowe dane techniczne trolejbusów Solaris Trollino 12 / Medcom.

\begin{tabular}{|c|c|}
\hline Moc silnika trakcyjnego & $175 \mathrm{~kW}$ \\
\hline $\begin{array}{l}\text { Maksymalna moc na wale silnika } \\
\text { podczas jazdy autonomicznej }\end{array}$ & $70 \mathrm{~kW}$ \\
\hline $\begin{array}{l}\text { Maksymalne przyśpieszenia podczas } \\
\text { jazdy autonomicznej }\end{array}$ & $0,4 \mathrm{~m} / \mathrm{s}^{2}$ \\
\hline Napięcie baterii & $201,6 \mathrm{~V}$ \\
\hline Maksymalny prąd baterii & $400 \mathrm{~A}$ \\
\hline Liczba ogniw & 168 \\
\hline Pojemność ogniw & $80 \mathrm{Ah}$ \\
\hline Typ ogniw & $\begin{array}{c}\text { NiCd } \\
\text { STH } 800\end{array}$ \\
\hline $\begin{array}{c}\text { Prąd ładowania szybkiego / standar- } \\
\text { dowego }\end{array}$ & $1 \mathrm{C} / 0,1 \mathrm{C}$ \\
\hline Masa baterii wraz z przekształtnikiem & $800 \mathrm{~kg}$ \\
\hline
\end{tabular}

Należy nadmienić, że baterie trakcyjne zostały zastosowane także w trolejbusach Mercedes O405N budowanych we własnym zakresie przez PKT Gdynia na bazie wycofanych z eksploatacji autobusów. W odróżnieniu od pojazdów Trollino, zastosowano w nich baterie o mniejszej pojemności, składające się z 60 ogniw STH 800. W celu uproszczenia aparatury elektrycznej zrezygnowano $\mathrm{w}$ nich także $\mathrm{z}$ montażu przetwornicy podwyższającej napięcie baterii - układ

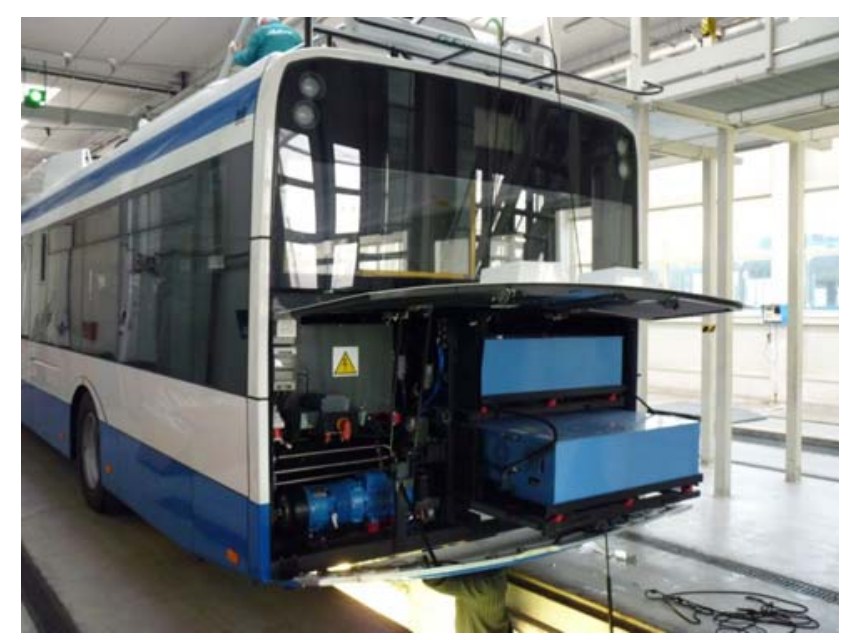

Fot. 2. Baterie trakcyjne (dwie niebieskie skrzynie z prawej strony) oraz przekształtnik baterii (lewa strona) trolejbusu Solaris Trollino 12 / Medcom. Autor: Mikołaj Bartłomiejczyk

napędowy jest zasilany bezpośrednio z baterii napięciem $72 \mathrm{~V}$ i pracuje przy znacznie ograniczonych parametrach ruchowych.

\section{Doświadczenia eksploatacyjne}

Trolejbusy wyposażone w pomocniczy napęd bateryjny są eksploatowane przez PKT Gdynia od stycznia 2010 r. W tym czasie możliwość jazdy autonomicznej była wielokrotnie wykorzystywana, zarówno podczas planowanych remontów ulic, jak i w trakcie sytuacji awaryjnych. Wszystkie pojazdy Solaris Trollino 12, które były zakupione od 2009 r. (do kwietnia 2011 r. dostarczono łącznie 21 pojazdów), są wyposażone w układ ciagłej rejestracji parametrów pracy pojazdu, m.in. stanu pracy baterii trakcyjnych. Na bazie tych rejestracji została sporządzona analiza dotychczasowych wyników eksploatacyjnych baterii znajdujących się w siedemnastu trolejbusach Solaris Trollino 12/ Medcom.

Jedna z sytuacji wykorzystania pomocniczego, bateryjnego źródła zasilania miała miejsce w dniach 19-21 listopada 2010 r. podczas zamknięcia ulicy Chwaszczyńskiej na czas wymiany asfaltowej nawierzchni. Wówczas trolejbusy pokonywały, korzystając z autonomicznego źródła zasilania, odcinki o długości 0,8 $\mathrm{km}$ do $2,2 \mathrm{~km}$ (w zależności od etapu prac drogowych). Na rys. 1 przedstawiono zależność stopnia rozładowania baterii od długości pokonanego odcinka, sporządzoną na podstawie rejestracji stanu pracy baterii podczas tego okresu.

Jak zaznaczono, napęd akumulatorowy miał także zastosowanie podczas sytuacji awaryjnych, m.in. uszkodzeń sieci trakcyjnej, awarii zasilania lub zaburzeń ruchu drogowego. Na rys. 2 znajduje się zależność pomiędzy głębokością rozładowania baterii trakcyjnych a pokonanym dystansem w sytuacjach awaryjnych, sporządzona na bazie doświadczeń eksploatacyjnych z lat $2010-2011$. 


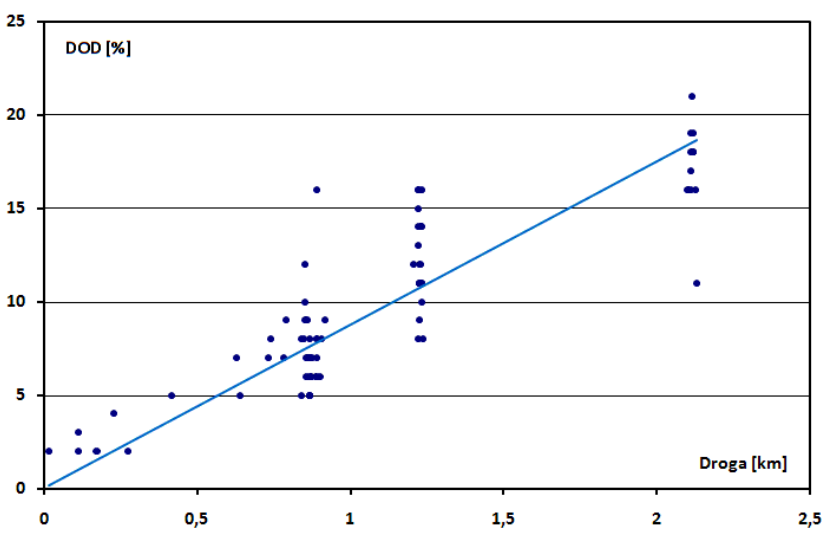

Rys. 1. Zależność pomiędzy stopniem rozładowania baterii a przejechanym dystansem sporządzona na bazie rejestracji z 19-21 listopada 2010.

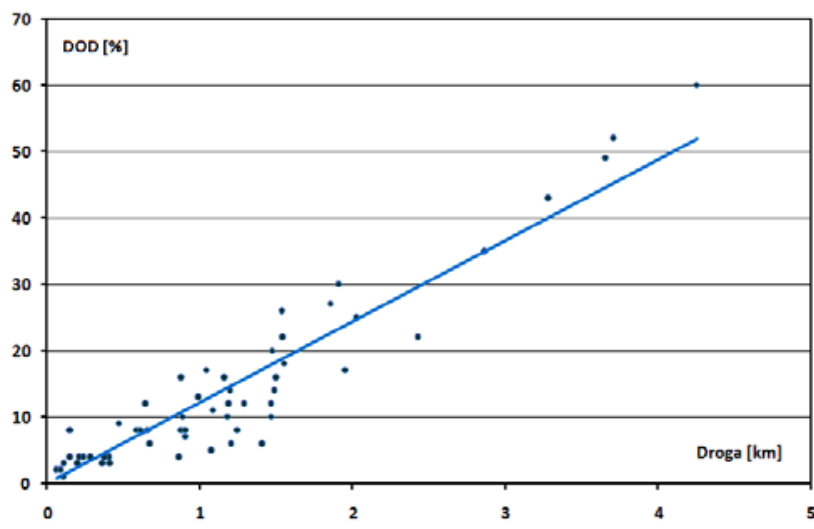

Rys. 2. Zależność pomiędzy stopniem rozładowania baterii a przejechanym dystansem w sytuacjach awaryjnych.

W tab. 2 przedstawiono podstawowe parametry energetyczne pomocniczego napędu bateryjnego uzyskane na podstawie eksploatacji przez PKT Gdynia siedemnastu trolejbusów Solaris Trollino 12 / Medcom od 2009 r. Na ich podstawie można stwierdzić, że w standardowych warunkach ruchu ulicznego zużycie energii, przez trolejbus przy jeździe autonomicznej - zasilaniu z baterii, kształtuje się na poziomie $1,5 \mathrm{kWh} / \mathrm{km}$, co przy założeniu zalecanego z punktu widzenia żywotności rozładowania baterii w $20 \%$, umożliwia przejazd dystansu o długości rzędu 2,2 km. Zużycie energii podczas jazdy $\mathrm{w}$ sytuacjach awaryjnych jest większe o $25 \%$. Wynika to z występujących utrudnio- nych warunków ruchu drogowego, czyli zatorów ulicznych oraz zwiększonej liczby zatrzymań i rozruchów. Najdłuższy dystans pokonany przy pomocy baterii trakcyjnych podczas jazdy z pasażerami wyniósł ponad $7 \mathrm{~km}$. Należy zaznaczyć, że ze względu na rzadkie występowanie sytuacji awaryjnych możliwie jest wówczas dopuszczenie głębszego rozładowania baterii, do poziomu 50-60 \%.

Zarówno w przypadku jazdy planowej, jak i awaryjnej, widoczny jest znaczny rozrzut pomiędzy maksymalnym i minimalnym zużyciem energii przez pojazdy. Poza zmiennymi warunkami ruchu i zróżnicowanym napełnieniem pojazdów istotną przyczyną są indywidualne umiejętności jazdy kierowców. Czynnik ten świadczy o potencjalnych możliwościach akumulatorowego zasobnika energii. Możliwe jest zwiększenie zasięgu pojazdów w przypadku przeprowadzenia szkolenia kierowców pod kątem optymalizacji techniki prowadzenia pojazdu.

\section{Baterie litowe - kolejny etap}

Decyzję o zakupie trolejbusów dla Gdyni - wraz z wyborem technologii zastosowanych baterii - podejmowano w 2008 roku. Od tego czasu zaszedł znaczny postęp technologiczny i realną alternatywą dla napędu pojazdów elektrycznych stały się baterie litowo - jonowe, dotychczas znane głównie z zastosowań w telefonach komórkowych, komputerach i aparatach fotograficznych.

Jako przykład praktycznego zastosowania baterii litowo jonowych można przedstawić trolejbus OAF Graf \& Sfift NGE 152 M17 hybrid, który znajduje się w eksploatacji w niemieckim mieście Eberswalde. Podczas jazdy bezsieciowej zasilany jest on z hybrydowego zasobnika energii wyprodukowanego przez firmę RWR Railway Service GMBH, zawierającego:

- superkondersatory o pojemności energetycznej $0,4 \mathrm{kWh}$ dla zwiększenia efektywności hamowania odzyskowego,

Tab. 2. Porównanie pracy pomocniczego napędu bateryjnego w różnych warunkach ruchowych.

\begin{tabular}{|c|c|c|c|c|c|}
\hline Tryb pracy & $\begin{array}{c}\text { Dystans poko- } \\
\text { nany dla DOD } \\
=20 \%\end{array}$ & $\begin{array}{c}\text { Średnie zuży- } \\
\text { cie energii ** }\end{array}$ & $\begin{array}{c}\text { Minimalne } \\
\text { zużycie } \\
\text { energii* }\end{array}$ & $\begin{array}{c}\text { Maksymalne } \\
\text { zużycie ener- } \\
\text { gii* }\end{array}$ & $\begin{array}{c}\text { Największy } \\
\text { pokonany dy- } \\
\text { stans }\end{array}$ \\
\hline Symulacja & $2,25 \mathrm{~km}$ & $1,4 \mathrm{kWh} / \mathrm{km}$ & - & - & - \\
\hline Praca planowa & $2,28 \mathrm{~km}$ & $1,51 \mathrm{kWh} / \mathrm{km}$ & $\begin{array}{c}0,83 \\
\mathrm{kWh} / \mathrm{km}\end{array}$ & $2,36 \mathrm{kWh} / \mathrm{km}$ & $2,164 \mathrm{~km}$ \\
\hline Praca awaryjna & $1,63 \mathrm{~km}$ & $1,86 \mathrm{kWh} / \mathrm{km}$ & $\begin{array}{c}0,68 \\
\mathrm{kWh} / \mathrm{km}\end{array}$ & $2,72 \mathrm{kWh} / \mathrm{km}$ & $7,105 \mathrm{~km}$ \\
\hline
\end{tabular}

* wyznaczone dla dystansów powyżej $1 \mathrm{~km}$

** średnia ważona dystansem przejechanym w każdym kursie 
- litowe baterie o pojemności $12 \mathrm{kWh}$ mające ze zadanie zwiększenie zasięgu jazdy przy zasilaniu bezsieciowym, o masie $170 \mathrm{~kg}$.

Bateryjna część zasobnika składa się z 10 litowo jonowych modułów HEB 40/36 produkcji RWR o następujących parametrach technicznych:

- napięcie $36 \mathrm{~V}$, każdy moduł składa się z 10 ogniw Li-Ion,

- pojemność: $40 \mathrm{Ah}$,

- maksymalny prąd ładowania: chwilowy (30 s) 160 A, ciagły 80 A,

- maksymalny prąd obciążenia: $200 \mathrm{~A}$,

- masa: $17 \mathrm{~kg}$.

Każdy moduł jest wyposażony $\mathrm{w}$ indywidualny system sterowania. Ze względu na minimalną temperaturę pracy ogniw wynoszącą -20 stopni Celciusza, każdy $\mathrm{z}$ modułów jest w grzejnik elektryczny o mocy $50 \mathrm{~W}$.

Innym interesującym rozwiązaniem, które było proponowane przez czeską firmę Czetro do zastosowania w trolejbusach w słowackim mieście Bańska Bystrzyca, był zasobnik energii oparty wyłącznie na ogniwach LiIon. Przewidziany było on zarówno do akumulacji energii hamowania odzyskowego podczas pracy sieciowej oraz bezsieciowej (trolejbus nie miał być wyposażony $\mathrm{w}$ rezystor hamowania) jak i do zasilania pojazdu $\mathrm{w}$ trakcie poruszania się bez zasilania $\mathrm{z}$ sieci trakcyjnej.

Dane tego zasobnika są następujące:

- 180 ogniw Li-Ion o pojemności $90 \mathrm{Ah}$,

- pojemność energetyczna $52 \mathrm{kWh}$,

- masa $650 \mathrm{~kg}$,

- objętość 3401 ,

- maksymalny zasięg trolejbusu podczas jazdy autonomicznej $30 \mathrm{~km}$.

W stanie jazdy przy zasilaniu z sieci trakcyjnej poziom naładowania baterii miał być utrzymywany na poziomie $90 \%$, co umożliwiało by przyjęcie energii hamowania. Przy jeździe autonomicznej dopuszczalny poziom rozładowania przewidywany był na poziomie $40 \%$.

Po uzyskanych pozytywnych doświadczeniach eksploatacyjnych $\mathrm{z}$ bateriami niklowo - kadmowymi Przedsiębiorstwo Komunikacji Trolejbusowej również rozważa budowę testowego trolejbusu wyposażonego w baterie litowo - jonowe. Przewidywane są następujące parametry zasobnika:

- 120 ogniw Li-Ion o pojemności $75 \mathrm{Ah}$,

- pojemność energetyczna $33 \mathrm{kWh}$,

- napięcie całkowite $444 \mathrm{~V}$,

- masa $190 \mathrm{~kg}$,

- maksymalna moc chwilowa $200 \mathrm{~kW}$.

Zasobnik ten umożliwi cykliczną obsługę odcinka pozbawionego sieci trakcyjnej o długości $5 \mathrm{~km}$.

\section{Podsumowanie}

Doświadczenia zyskane podczas dotychczasowej, blisko dwuletniej eksploatacji trolejbusów wyposażonych $\mathrm{w}$ alternatywne źródło zasilania w postaci baterii trakcyjnych, potwierdzają słuszność wyboru tego rozwiązania. Alternatywny napęd bateryjny w zasadniczy sposób zwiększa mobilność trolejbusów zarówno podczas planowych zmian organizacji ruchu ulicznego, jak i awarii, jednocześnie pozwalając na zachowanie podstawowej zalety komunikacji trolejbusowej, czyli braku emisji spalin w miejscu pracy. Postęp w dziedzinie baterii elektrochemicznych daje możliwości dalszego rozwoju trolejbusów z napędem autonomicznym.

\section{Bibliografia}

[1] Bartłomiejczyk M., Połom M.: Eksploatacja i rozwój infrastruktury oraz taboru Przedsiębiorstwa Komunikacji Trolejbusowej w Gdyni, Konferencja MET 2009 Krynica Morska, Gdańsk 2009

[2] Bartłomiejczyk M.: Trolejbus z autonomicznym źródtem zasilania, Zeszyty Naukowe Wydziału Elektrotechniki $i$ Automatyki Politechniki Gdańskiej Nr 27, 2010

[3] Giziński Z., Gasiewski M., Zych M., Żuławnik M.: Hybrydowy uktad zasilania trolejbusu. Technika Transportu Szynowego 9/2007,

[4] Kacprzak J., Kozierkiewicz M.: Układy napędowe $i$ układy sterowania trolejbusów, Radom, Oficyna Wydawnicza Politechniki Radomskiej 1997

[5] Maciołek T., Drażek Z.: Tramwaj z zasobnikiem kondensatorowym na odcinku bez zasilania. Konferencja MET 2005, Warszawa, 2005

[6] Połom M., Palmowski T.: Rozwój i funkcjonowanie komunikacji trolejbusowej w Gdyni, Gdańsk, Oficyna Wydawnicza Uniwersytetu Gdańskiego 2009

[7] Pankowski R.: Zastosowanie poktadowego zasobnika energii $w$ trolejbusie. Politechnika Gdańska, praca dyplomowa magisterska. Gdańsk 2009. 